\title{
Screening refrigerant for a new enhanced ejector heat exchanger used in district heating system based on industrial waste heat
}

\author{
Fangtian Sun ${ }^{*}$, Baoru Hao, and $X u$ Chen \\ Beijing Research Center of Sustainable Energy and Buildings, Beijing University of Civil \\ Engineering and Architecture, 100044 Beijing, China
}

\begin{abstract}
Performance of the new enhanced ejector heat exchanger is the key to improving performance of the district heating system based on industrial waste heat, and it is significantly affected by thermo-physical property of refrigerant. In this paper, characteristics of the new enhanced ejector heat exchanger are considered, and a new principle for screening refrigerant is proposed. Eleven kinds of refrigerants are firstly selected as candidates, and then they are evaluated from the perspective of property and thermodynamic performance of the new enhanced ejector heat exchanger. The results show that refrigerant property has a greater influence on thermodynamic performance of the new enhanced ejector heat exchanger. Under the condition of low temperature space heating, R152a and R1234yf are favorable choices for the new enhanced ejector heat exchanger. While under conditions of other temperature space heating, R245fa and R600 are better choices for the new enhanced ejector heat exchanger.
\end{abstract}

Keywords: Screening refrigerant; Enhanced ejector heat exchanger; Heat-driven ejector refrigeration; heat transfer effectiveness; product exergy efficiency

\section{Introduction}

Lowering return temperature of the primary heating network helps to recover industrial waste heat efficiently by using a water-to-water heat exchanger on the side of the waste heat source [1-2]. F. Sun et al [3] point out that a new enhanced ejector heat exchanger that consists of a heat driven ejector refrigeration system and a water-to-water heat exchanger could be used to greatly reduce the return temperature of the primary heating network in the heating substation.

Performance of the new enhanced ejector heat exchanger mainly depends on performance of the heat-driven ejector refrigeration system in it. For the heat-driven ejector refrigeration system, its performance is affected, to a large extent, by thermo-physical property of

\footnotetext{
*Corresponding author: sunfangtian@bucea.edu.cn
} 
refrigerant [4], and generating temperature, evaporating temperature and condensing temperature are affected each other. F. Wan et al [5] point out that each refrigerant has a specific efficient operating temperature zone, in which performance of the conventional heatdriven ejector refrigeration system with the specific refrigerant is higher than that with other refrigerants. J. Chen et al [6] show that performance of the conventional heat-driven ejector refrigeration system with R141b is better than that with R245fa or R600a. X. Chen et al [7] point out that $\mathrm{CO}_{2}$ with lower critical temperature, $\mathrm{H}_{2} \mathrm{O}$ with larger specific volume, and $\mathrm{NH}_{3}$ with flammility and toxicity could be used in the conventional ejector refrigeration systems, but everyone has a certain shortcoming in practical application. In summary, each refrigerant has a specific efficient operation condition, and it has certain limitation in practical application.

Compared with the conventional heat-driven ejector refrigeration system, the heat-driven ejector refrigeration system in the enhanced ejector heat exchanger has higher operating temperature, and more complicated working mechanism. Thus, screening refrigerant for the new enhanced ejector heat exchanger is necessary for higher performance. In this paper, a new principle of screening refrigerant is proposed. The best selection of refrigerants for the new enhanced ejector heat exchanger is analyzed when it is used in different working conditions.

\section{Screening refrigerant for new enhanced ejector heat exchanger}

\subsection{Principle of screening refrigerant}

For the conventional heat-driven ejector refrigeration system, the refrigerants are usually evaluated from the perspective of environmental effect, safety, economic benefit, and thermodynamic performance [8]. The new enhanced ejector heat exchanger is different in working mechanism from the conventional ejector refrigeration system, and it is closer to residential buildings, even installed inside the small space basement of residential buildings. Thus, new principle of screening refrigerant for the enhanced ejector heat exchanger would pay more focus on the safety, heat transfer performance, and thermodynamic performance.

In view of above requirements, a new principle of screening refrigerant for the new enhanced ejector heat exchanger is presented as follows:

(1) Environmental effects: Naught or smaller Ozone Depression Potential (ODP), and naught or smaller Global Warming Potential (GWP).

(2) Safety: Lower toxicity or non-toxicity, low flammability or non-flammability, and non-corrosive.

(3) Thermo-physical properties: Larger value of latent heat, lower operating pressure, and favorable heat transfer property.

(4) Thermal performance: Higher heat transfer effectiveness and product exergy efficiency.

According to the newly proposed principle of screening refrigerant, R141b, R123, R134a, R152a, R227ea, R236fa, R245fa, R600, R1234yf, R1234ze and RC318 are selected firstly as candidates.

\subsection{Evaluation of refrigerant properties}

ASHARE Standard 34-2016 [9] illustrates data of refrigerant's safety, environmental effect in details, such as lethal concentration for $50 \%$ of tested animals for a specified time interval and for different animal species (LC50), threshold limit value-time-weighted average (TLVTWA), and lower flammability limit (LEL). For a specific refrigerant, the bigger values of 
the TLV-TWA, LEL and LC50 are, the higher its safety is. The safety and environmental effect data of the candidate-refrigerants are listed in Table 1.

Table 1. Safety and environmental effect of the candidate-refrigerants.

\begin{tabular}{ccccccc}
\hline Refrigerant & GWP & ODP & $\begin{array}{c}\text { Atmospheric life } \\
(\text { year })\end{array}$ & $\begin{array}{c}\text { TLV-TWA } \\
(\mathrm{ppm})\end{array}$ & $\begin{array}{c}\text { LFL } \\
(\mathrm{ppm})\end{array}$ & $\begin{array}{c}\text { LC50 } \\
(\mathrm{ppm})\end{array}$ \\
\hline R141b & 700 & 0.086 & 9.2 & 500 & 60,000 & 61,600 \\
R123 & 120 & 0.012 & 1.4 & 50 & - & 32,000 \\
R134a & 1600 & 0 & 13.6 & 1000 & - & $>359,000$ \\
R152a & 190 & 0 & 1.5 & 1000 & 48,000 & 400,000 \\
R227ea & 3800 & 0 & 36.5 & 1000 & - & $>788,696$ \\
R236fa & 9400 & 0 & 226 & 1000 & - & $>457,000$ \\
R245fa & 820 & 0 & 8.8 & 300 & - & $>203,000$ \\
R600 & 20 & 0 & 12.0 & 1000 & 20,000 & 272,000 \\
R1234ze & $<1$ & 0 & 0.029 & 800 & 65,000 & $>207,000$ \\
R1234yf & 4 & 0 & 0.029 & 500 & 62,000 & $>406,000$ \\
Rc318 & 11200 & 0 & 3200 & 1000 & - & $>800,000$ \\
\hline
\end{tabular}

All environmental effect and safety of refrigerant considered, the preferred order of the candidate-refrigerants for the new enhanced ejector heat exchanger is given as follows: R134a, R236fa, R152a, R1234ze, R600, R245fa, R1234yf, RC318, R227ea, R141b, and R123.

It is noted that, according to requirements of Regulation (EU) No 517/2014 [10], R123, R227ea, R236fa, and RC318 will be banned from being used in Europe since January 1, 2020; R134a, R152a and R245fa will be banned from being used in Europe since January 1, 2022.

\section{Results and discussion}

In Northern China, the design temperature of supply and return water of the secondary heating network can be divided into four categories: (1) $40{ }^{\circ} \mathrm{C}$ and $30{ }^{\circ} \mathrm{C}$; (2) $60{ }^{\circ} \mathrm{C}$ and $45{ }^{\circ} \mathrm{C}$; (3) $70{ }^{\circ} \mathrm{C}$ and $55{ }^{\circ} \mathrm{C}$; (4) $80{ }^{\circ} \mathrm{C}$ and $65{ }^{\circ} \mathrm{C}$.

For the new enhanced ejector heat exchanger, the significant difference among the candidate-refrigerants is located in power consumption of both refrigerant pump and pressure booster, which results in difference of thermodynamic performance. The ratio of heat output to electricity input is used to analyze the role in improving heat transfer performance of the new enhanced ejector heat exchanger played by the pressure booster. The ratios of heat output to electricity input of the new enhanced ejector heat exchanger with candidate-refrigerants are shown in Fig.1.

Fig. 1 illustrates that the lower heating temperature for heat users results in larger ratio of heat output to electricity input for the specific refrigerant. It indicates that the enhanced ejector heat exchanger is more suitable to be applied in the district heating system with low temperature heat users.

Product exergy efficiency is also used to evaluate thermodynamic performance of the new enhanced ejector heat exchanger. Product exergy efficiencies of the new enhanced ejector heat exchanger with candidate-refrigerants are shown in Fig. 2.

As can be seen from Fig. 2 that product exergy efficiency of the enhanced ejector heat exchanger is higher at the design supply/return temperature of $60{ }^{\circ} \mathrm{C} / 45^{\circ} \mathrm{C}$ and $70{ }^{\circ} \mathrm{C} / 55^{\circ} \mathrm{C}$. For the same candidate-refrigerant, product exergy efficiency of the enhanced ejector heat exchanger is different under the conditions of different heating temperature. 


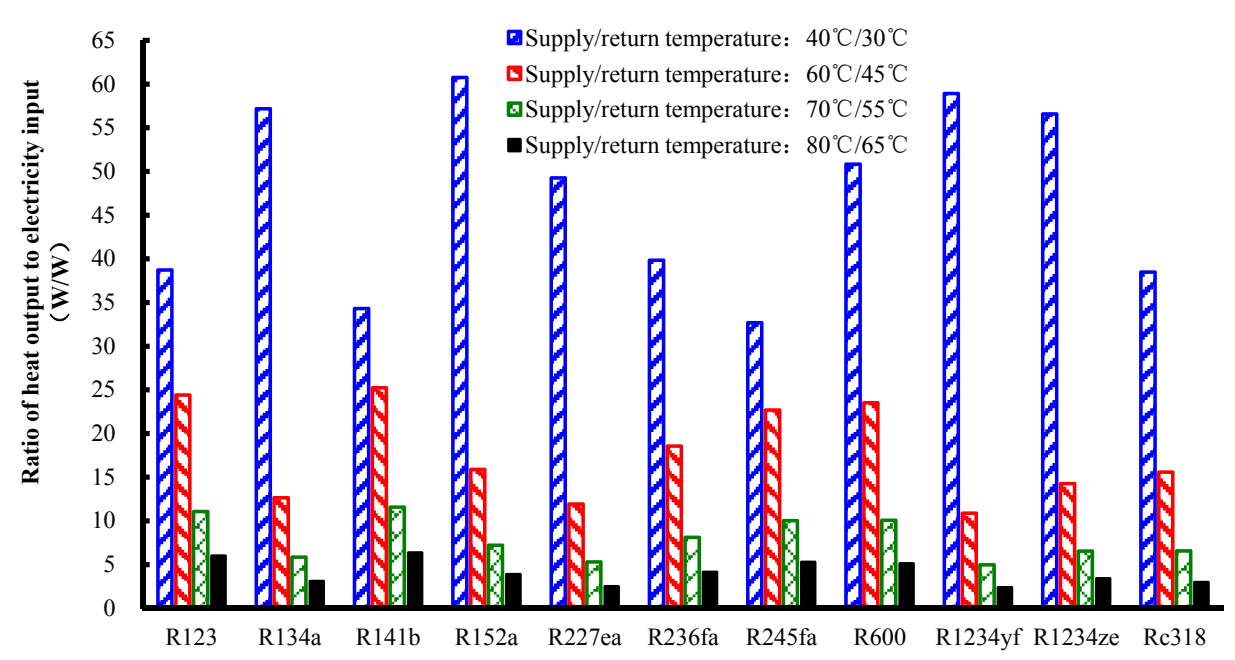

Fig. 1. Ratio of heat output to electricity input of new enhanced ejector heat exchanger.

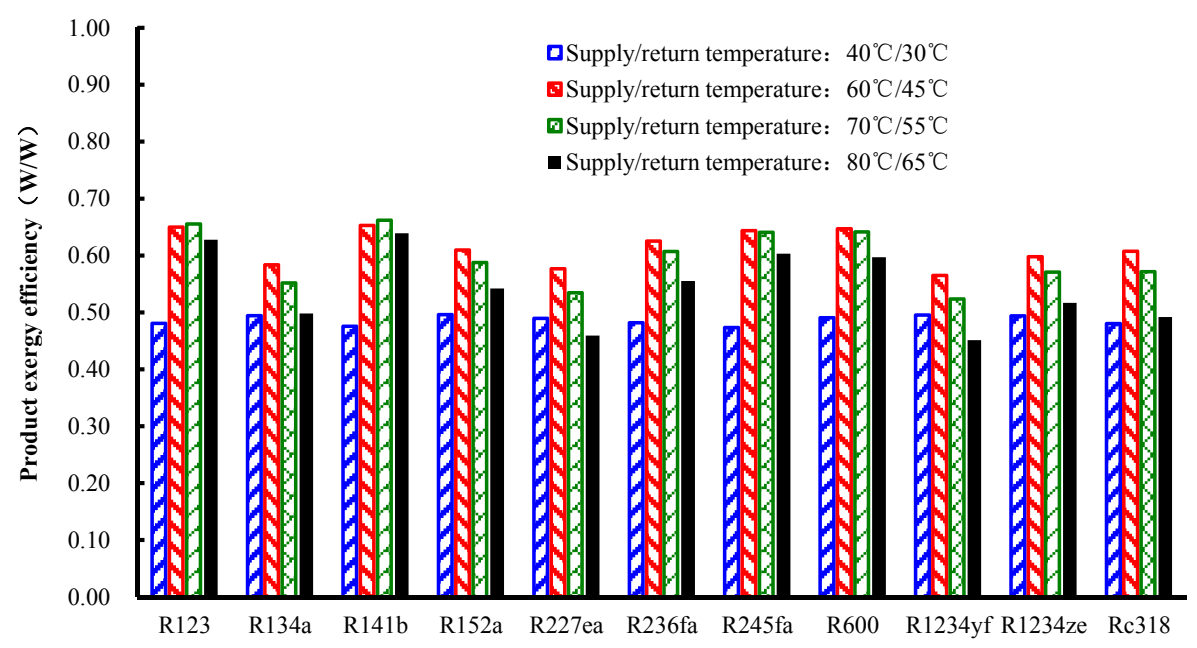

Fig. 2. Production exergy efficiency of the new enhanced ejector heat exchange.

From the perspective of heat transfer performance and thermodynamic performance, R152a, R1234yf, R134a and R1234ze are better choices for the new enhanced ejector heat exchanger when the design supply / return temperature is $40^{\circ} \mathrm{C} / 30^{\circ} \mathrm{C}$. With regard to other design supply/return temperatures, R141b, R123, R245fa and R600 are better choices for the new enhanced ejector heat exchanger.

\section{Conclusion}

In this paper, characteristics of the new enhanced ejector heat exchanger are considered, and a new principle for screening refrigerant is proposed, and eleven kinds of candidaterefrigerants are evaluated and screened from the perspective of refrigerant property, heat transfer performance and thermodynamic performance of the new enhance ejector heat exchanger. Some important conclusions are drawn as follows:

(1) Since some of the new ejector heat exchangers are installed inside the basement of resident buildings, new screening principle of candidate-refrigerants not only abides by the 
current screening principle of refrigerants used for the conventional heat-driven ejector refrigeration system, but pay more attentions to safety of refrigerant and thermal performance of the new enhanced ejector heat exchange.

(2) R152a and R1234yf are favorable choices for the new ejector heat exchanger when the design supply / return temperature of the secondary heating network is $40{ }^{\circ} \mathrm{C} / 30{ }^{\circ} \mathrm{C}$.

(3) With respect to other design temperatures of the secondary heating network, R245fa, and R600 are better choices for the new enhanced ejector heat exchanger.

(4) For higher design temperature of the secondary heating network, heat transfer effectiveness and thermodynamic performance of the new enhanced ejector heat exchanger with R141b is higher than that with other candidate-refrigerants. However, its significant shortcoming is that Ozone Depression Potential is slightly higher than 0. If R141b is managed well in the process of actual application, it would be a better choice for the new enhanced ejector heat exchanger under the condition of higher design temperature of the secondary heating network.

\section{Acknowledgement}

Thanks to the Beijing municipal commission of education science and technology program (KM201810016007), and the Beijing Key Laboratory of Heating, Gas Supply, Ventilating and Air Conditioning Engineering.

\section{Reference}

1. Fangtian Sun, Lin Fu, Jian Sun, Shigang Zhang, A new waste heat district heating system with combined heat and power (CHP) based on ejector heat exchangers and absorption heat pumps, Energy 69 (2014) 516-524.

2. Hao Fang, Jianjun Xia, Yi Jiang, Key issues and solutions in a district heating system using low-grade industrial waste heat, Energy 86 (2015) 589-602.

3. Fangtian Sun, Xu Chen, Lin Fu, Shigang Zhang, Configuration optimization of an enhanced ejector heat exchanger based on an ejector refrigerator and a plate heat exchanger, Energy 164 (2018) 408-417.

4. Giorgio Besagni, Riccardo Mereu, Fabio Inzoli, Ejector refrigeration: A comprehensive review, Renew. Sustain. Energy Rev. 53 (2016) 373-407.

5. F. Wang, D.Y. Li, Y. Zhou, Theoretical research on the performance of the transcritical ejector refrigeration cycle with various refrigerants, Appl. Therm. Eng. 91 (2015) 363369.

6. Jiangyong Chen, Hans Havtun, Bjorn Palm, Parametric analysis of ejector working characteristics in the refrigeration system, Appl. Therm. Eng. 69 (2014) 130-142.

7. Xiangjie Chen, Siddig Omer, Mark Worall, Saffa Riffat, Recent developments in ejector refrigeration technologies, Renew. Sustain. Energy Rev. 19 (2013) 629-651.

8. Jiangyong Chen, Hans Havtun, Bjorn Palm, Screening of working fluids for the ejector refrigeration system, Int. J. Refrig. 47 (2014) 1-14.

9. ASHRAE, ANSI/ASHRAE Standard 34-2016, Designation and Safety Classification of Refrigerants, Atlanta, 2016.

10. REGULATION (EU) No 517/2014 OF THE EUROPEAN PARLIAMENT AND OF THE COUNCIL of 16 April 2014 on fluorinated greenhouse gases and repealing Regulation (EC) No 842/2006. Official Journal of the European Union, 2014. 